\title{
Circular / comunicar / contactar- o espaço público como índice de transformação da cidade*
}

\footnotetext{
*Em sua primeira versão, e com o nome Comunicação e Cultura: publicar e deslocar, este trabalho foi apresentado na XII Compós - Recife - Junho - 2003 Grupo de Trabalho Comunicação e Cultura.
}

LuCRÉcia D’Alessio FerRara Universidade Tuiuti do Paraná/UTP 


\section{Resumo}

Este trabalho estuda os processos interativos que têm como cenário e ator o espaço público ao agasalhar distintas características culturais, comunicativas e semióticas e sofrer impactos sociais e tecnológicos que o levam a ultrapassar sua dimensão física e territorial. Nesse percurso, o espaço público é teatro e cenografia da cidade cosmopolita, desloca-se com a mídia eletrônica e virtualiza-se com a mídia digital.

Palavras-chave

comunicação, interação, cultura, espaço público

\section{Abstract}

This work analyze the interactive process who has the public space like agent and scene. In this way, space sheltes some cultural, communicative and semiotc characteristics and he suffers social and technological shocks. In consequence he exceeds physical and territorials limits and shows differents meanings through cosmopolitan, peersuasive and virtual public space.

Key words

communication, interaction, culture, public space 


\section{O mega-mundo}

lobalização e mundialização são neologismos que designam U um mundo novo. Na globalização, o mundo é uma imensa cidade produzida pela colagem de outras cidades pequenas e grandes, reconhecidas e desconhecidas, diferentes e parecidas: esta cidade fantástica é o mega mundo tecnológico das metrópoles mediadas e produzidas pela relação complexa de múltiplas características econômicas, sociais e culturais.

O mega-mundo feito de cidades dentro de cidades trocou o território pela conurbação real e virtual e o lugar logocêntrico pela agitação policromática, polivisual, polifônica e, sobretudo, cinética e em constante mudança.

Nunca como no mega mundo, se utilizou tanto a analogia com a Torre de Babel para concretizar a confusão da cidade global onde todos os opostos se congregam em disputa acirrada, mas já assumida e inexorável. Mundialização e tecnologia caracterizam o tempo presente e, contaminadas, não permitem raciocínios apocalípticos que caracterizaram a interpretação do pensamento intelectual do pós-guerra, temente de uma ação capaz de dizimar a humanidade submissa à máquina e à comunicação manipuladoras. Ao contrário dessa posição, é necessário analisar as novas formas de ação desenvolvidas pelos meios de comunicação no mundo social e, sobretudo, as outras relações comunicativas que transformam as ações coletivas e o domínio individual. Porém, essa análise depende de uma suficiente compreensão da mudança introduzida pelos novos meios e o caminho mais concreto se concentra na comparação entre os desenhos do tempo e do espaço de ontem e de hoje e, como 
exemplo, estuda-se a notável transformação da funcionalidade do espaço público, entendido como manifestação cultural cujos signos se identificam nas suas características de uso.

Para tanto, não é possível analisar a comunicação globalizada exclusivamente no contexto técnico da sua produção, circulação e recepção, mas é necessário comparar os alicerces da mudança, ou seja, é necessário entender a dimensão histórica da nova comunicação mediada que se caracteriza como processo em curso sem metas prefixadas e onde, no atual momento, o mega mundo se divide proporcionalmente entre o tempo que se encolhe e o espaço que se perde. A globalização da economia mas sobretudo, a desterritorialização da cultura graças às novas tecnologias da comunicação estabelecem uma sensível mudança no uso e na percepção das cidades. O espaço público urbano constitui elemento vital na caracterização dessa mudança que o leva a atingir uma outra etapa, inscrevendo-o como espaço público mediado. Agora, o espaço público e seu uso constituem uma curiosa variável onde se pode perceber ganhos e perdas que a simples constatação descritiva das características tecnológicas dos meios comunicativos não logra perceber.

Partindo do espaço público como estudo de caso, o presente trabalho se orientará metodologicamente pela discriminação das dimensões semióticas e comunicativas do espaço de ontem para compará-lo com as dimensões do espaço público atual.

Em 1974, Richard Sennett publicou uma obra fundamental denominada O Declínio do Homem Público. Em 2002, as descrições e, sobretudo, as argumentações daquela obra parecem estranhas e sem sentido. Porém, passar em revista os meandros daqueles argumentos nos permitirá entender o antídoto da cidade cosmopolita e criar um dispositivo heurístico capaz de produzir uma estrutura analítica mais rigorosa que poderá nos levar a entender o inverso do espaço público do século 19 e início do 20, ou talvez, seu anverso contraditório: a cidade virtual. Da cidade cosmopolita à virtual, o eixo de contaminação, comparação e transformação está nas características de um espaço público que vai da praça à infovia. 


\section{O declínio do homem público}

O título da obra de Sennett era paradoxalmente complementado por um subtítulo "As Tiranias da Intimidade" que nos induz a entender imediatamente que o público só era passível de compreensão através do privado. Porém, essa é a característica do espaço público do século 19.

O mundo greco-romano procurava construir, entre o público e o privado, um equilíbrio que desconsiderava uma oposição entre ambos, para descobri-los como corretivos mútuos e criadores de um princípio de equilíbrio (Sennett,1988, p.15). O mundo medieval até o início do Renascimento, ao contrário, via, na praça pública, a síntese de um mundo extra-oficial e anti-hierárquico onde as expressões orais se combinavam aos gestos grotescos e, paradoxalmente, permitiam a emergência de um padrão oficial do espaço privado e, por isso mesmo, reconhecido como legítimo: liberdade, franqueza e carnaval eram a outra face assumida e reconhecida que justificavam a legitimidade das normas de etiqueta, da hierarquia e do comportamento palacianos (Bakhtin,1974, p. 139). Ou seja, até o final do renascimento, o público e o privado eram entendidos como instâncias distintas, mas equilibradas e mútuo-corretivas.

A cultura do espaço público é obra do século 18, seu apogeu está marcado pela emergência da cidade cosmopolita do século 19 e pela fruição da vida pública dos bulevares, cafés e passagens até a eclosão da definitiva incorporação das transformações culturais introduzidas pela Revolução Industrial mecânica que agrupou, de um lado, produção e consumo e, de outro lado, reprodutibilidade técnica e percepção sem compromissos estéticos e míticos. (Benjamim, 1975, pp. 15,16) A divisão entre o eu e o nós, entre o privado e o coletivo, entre o particular e o comum caracteriza os pólos em oposição na cidade cosmopolita, porém, a questão se torna mais complexa quando essa relação se define pelo caráter comunicativo de dois parâmetros culturais e sociais em confronto num local: surge a clara noção do espaço público.

Portanto, a arqueologia do espaço público deve ser procurada na gênese da cidade cosmopolita do século 18 e nas construções 
semióticas que o identificaram e consideraram aquele espaço como matriz da cultura moderna:

Em sociedades de grande pobreza, de hierarquias rígidas ou de paixões religiosas muito fortes, a gratificação psíquica só pode ter pouco sentido enquanto um fim em si mesmo. Este clamor peculiar da natureza contra a cultura começou a tomar forma no Século XVIII, especialmente na Inglaterra, na França, no norte da Itália e no nordeste dos Estados Unidos. Como todo desenvolvimento histórico complexo, ele não nasce de um só golpe. Nossos antepassados lutaram para encontrar imagens e experiências que pudessem de algum modo exprimir essa oposição, de maneira a atribuir uma forma social concreta à busca da felicidade. Um dos caminhos que utilizaram para exprimi-lo foi por meio da distinção entre $o$ público e o privado. A geografia das capitais servia aos cidadãos como meio para pensarem sobre natureza $e$ cultura, identificando o natural com o privado e a cultura com o público. (Sennet, 1988, p. 118)

A citação deixa claro que o signo e a cultura são do domínio público e sua relação comunicativa se desenvolve naquele espaço. Resta saber como se fazem significantes e se constroem semioticamente.

\section{A cultura do espaço público}

Descrever as características e interpretar as dimensões culturais da modernidade têm atraído a atenção de muitos filósofos no decorrer do século 20. A construção dessa "arqueologia da modernidade" tem sugerido, como ponto de partida, o estudo da situação do espaço público como teatro daquela cultura.

Do "flâneur" e das passagens de Benjamim até a Teoria da Esfera Pública e da Ação Comunicativa de Habermas nos defrontamos com interpretações do espaço público como território localizado da cultura. A emergência dos meios de comunicação de massa nos 
meados do século 20 e a crescente globalização econômica do planeta sustentada pela tecnologia eletrônica e digital da informação e da comunicação impõem outra dimensão interpretativa do espaço público e passamos da sua localização territorial para o deslocamento midiático e virtual.

Dentre os vários estudiosos dessa característica da relação pública, John Thompson (1998) salienta como pólo de distinção entre aqueles espaços suas características interativas. Assim, aponta três padrões interativos: a interação face a face como relação comunicativa de troca e proximidade, a interação mediada como espaço de relação à distância e a interação quase mediada como forma de relação tecnológica e banalizadora da distância física.

Nessa classificação, o eixo interpretativo apóia-se, de um lado, no estudo da relação comunicativa, mas não considera suas características espaciais e públicas como consequiência e origem de uma percepção e relação comunicativas distintas, de outro lado, apreende-se os alicerces interativos como estanques e de manifestação discreta, ou seja, não considera as conseqüências do confronto e da comparação entre eles como fatores estimulantes da ação pública. Confrontálos e compará-los nos leva a entender um processo de interação que se subdivide em típico, tópico e atópico (Virilio, 1993, p. 13) na medida em que, em cada uma das suas modalidades, prescreve comportamentos interativos, proscreve o encontro e a troca e, virtualmente, se disponibiliza, sem expor-se ou obrigar. A proposta desse trabalho é estudar o espaço público como manifestação cultural que encontra, nos processos de relação comunicativa que agasalha e estimula, suas características básicas e identificadoras, não apenas do moderno, mas da modernidade enquanto fantástica operação de identidade cultural. Para tanto, é necessário, não apenas descrever a relação comunicativa, mas identificar as características semióticas capazes de construir distintas manifestações que deixam seus índices nos desenhos do espaço público. Estuda-se, portanto, a relação comunicativa localizada semioticamente no espaço territorial ou virtual, isto é, propõe-se sair de uma análise sociológica da relação entre os indivíduos, para estudar o espaço público como desenho semiótico de uma relação que define a dimensão da cultura de ontem e de hoje. 


\subsection{O espaço público como cultura do espetáculo}

O espetáculo caracteriza o espaço público localizado fisicamente no território e que encontra sua definição enquanto se opõe ao espaço privado. É o espaço que sustentou a construção do mundo mecânico do século 19 até as primeiras décadas do século 20.(Ferrara, 2000, p. 33) Essa oposição implica em dimensões distintas de comportamento. Desse modo, se o espaço privado caracteriza a intimidade que agasalha comportamentos emotivos do indivíduo recluso em si mesmo como amar, sofrer, chorar ou pensar; o espaço público alicerça comportamentos que exigem o coletivo como expressar, representar, jogar, trapacear, mostrar ou dividir. Se o espaço privado sugere a atmosfera confessional da solidão, o espaço da vida pública, ao contrário, supõe a troca e a comunicação. Se o espaço da vida privada está confinado à reclusão dos aposentos particulares ou aos salões vedados aos estranhos e aos não convidados; o espaço da vida pública está nos cafés, nos bulevares, jardins, parques, praças e avenidas, uma diversidade pública definida no espaço e no tempo. Essa oposição gera as duas grandes características do espaço público localizado: a representação e o diálogo que permitem a Thompson rotular a interação face a face.

Representação e diálogo, por sua vez, dão origem às estruturas semióticas daquele espaço: o logocentrismo e a expressividade do corpo e do gesto no espetáculo e na representação: corpo em exposição relacionado à palavra que o expressa e, ambos, capazes de sintetizar, em comunhão, uma retórica dominada pela metonímia que constitui a síntese da sua informação. Cada café, parque, praça ou avenida representa o mundo uniforme, porém dividido entre o coletivo e a intimidade.

O gesto e o corpo fazem do espaço público localizado um espetáculo onde se representa a auto-imagem: o figurino, a moda, o lazer, o sentar-se, o caminhar são índices típicos do espaço onde se representa essa publicidade do indivíduo totalmente distinto da vida privada; esse espetáculo é expresso pela palavra oral que consolida a tradição do povo em um território e constrói sua fabulação pela narração repetida das lembranças. É o espaço público dominado pelos 
valores e crenças que constituem o sistema de ordem de ações e de comportamentos aceitos coletivamente. A doxa e a hierarquia consolidam o diálogo e sustentam a troca comunicativa e informativa do tempo passado no espaço público localizado. Para decodificar essa tradição e sua cifrada linguagem é necessário partilhar o espaço e entender os índices de uma maneira de ser para ser visto. Essa participação permite a auto-identidade onde o sujeito se espelha e se reconhece no coletivo. Mais do que localizado, esse espetáculo é contextualizado pela dinâmica cultural de cada território.

Sob a aparente desordem da cidade tradicional, existe, nos lugares em que ela funciona a contento, uma ordem surpreendente que garante a manutenção da segurança $e$ da liberdade. É uma ordem complexa. Sua essência é a complexidade do uso das calçadas, que traz consigo uma sucessão permanente de olhos. Essa ordem compõe-se de movimento e mudança e, embora se trate de vida, não de arte, podemos chamá-la, na fantasia, de forma artística da cidade e compará-la à dança - não a uma dança mecânica, com os figurantes erguendo a perna ao mesmo tempo, rodopiando em sincronia, curvando-se juntos, mas a um balé complexo, em que cada indivíduo e os grupos têm todos papéis distintos, que por milagre se reforçam mutuamente e compõem um todo ordenado. $O$ balé da boa calçada urbana nunca se repete em outro lugar, e em qualquer lugar está sempre repleto de novas improvisações. (Jacobs, 2000, p. 52).

\subsection{O espaço público deslocado}

Os meios eletrônicos de informação geram um espaço público deslocado, não só da sua conexão física territorial, mas sobretudo cada vez mais distante da opinião, da doxa como código de comunicação oral da tradição. Deslocado, o espaço público tem sua anterior semiótica logocêntrica e gestual transformada em imagem. A tatilidade é substituída pelo olhar que, porém, não está livre e à 
vontade, mas programado à distância, é dirigido, conduzido por poderosos vetores especializados em produzir persuasão. Esta imagem monitorada invade, sem cerimônia, o espaço privado dos nossos dias e inaugura o espaço do entretenimento de massa que se destina a todos porque a ninguém identifica.

Essa programação encontra no espaço público seu apoio, mas ele não se localiza nos valores do tempo, ao contrário ele é deslocado porque é um espaço sem tempo, sem história, sem fabulação, sem valores próprios à sua publicidade. Isso deve ser suficiente para imaginar que esse espaço é fictício, um espaço possível, mas não real: esse é o espaço que ao ser programado visualmente, faz da publicidade um emblema e se desloca, se multiplica em espaços momentâneos e sem história que surgem tão rápido como podem desaparecer, constroem-se e destroem-se ao sabor dos interesses comerciais e das estratégias de mercado que os justificam. São os shoppings centers que substituem definitivamente os lugares de encontro e de troca afetiva do passado e que, no seu apelo de imagem expandem e espelham a ficção televisiva. É o espaço feito para ser consumido pelo hábito e pelo ócio sem compromissos com a necessidade de responder ou de reagir, mas culturalmente impositivo de um comportamento e de uma estética, nesta imposição disfarçada está sua tópica relacional. Trata-se de uma estranha interação que se processa a distância e, sobretudo, sem ação. Contenta-se com a fruição de um possível apenas montado pelos recursos ficcionais que sugerem supostas relações interativas com personagens que se tornam tão íntimas quanto distantes e apontam para um diálogo/ monológico de uma só voz onde o telespectador é, ao mesmo tempo, emissor e receptor e povoa seu cotidiano com figuras tecnológicas. Porém, a dinâmica desse "faz-de-conta" é implacável e, cada vez menos, ilude o expectador: enquanto simples voyeur ele parece ser presa fácil da distração e do cansaço, mas o zapping é sua negação interativa. e a flutuação da audiência é índice da sua resposta.

Essa publicidade disponível, mas não necessária, gera uma exacerbação da imagem que precisa ser insistente e reiterativa e, nessa dimensão, estão suas duas principais características. De um lado, essa insistência é autofágica, porque, ao contrário do espaço de 
frequentação e hábito, ele precisa ser constantemente maquiado como se novo e distinto fosse a fim de conseguir prender persuasivamente a atenção errante do espectador omisso e ocioso. De outro lado, essa imagem autofágica elege e ilumina alguns espaços em detrimento de outros. São os espaços iluminados pelo uso comercial, empresarial, econômico ou técnico do público, espaços de uma cultura tatuada pela imagem, pela luz e pela cor. São as tecnoesferas públicas que, programadas, impedem o livre exercício interpretante da geração de sentidos e subvertem a semiosfera que caracteriza o espetáculo público do espaço localizado.

$\mathrm{Na}$ realidade, nas duas dimensões do espaço temos espetacularização, porém com tônicas opostas. No primeiro caso, o espaço público faz da visualidade seu espetáculo, no espaço público deslocado, o receptor é apenas espectador, isto é, se submete ao espaço alienante da mídia e o espetáculo de cor, luzes e movimento da televisão invade todas as fronteiras, conquista todos os domínios e organiza a passividade, como aponta Guy Debord (1997). Nos dois casos, temos espetáculos, porém não se superpõem, ao contrário, distinguem-se: no caso do espaço público do encontro e da troca tem-se o espetáculo onde o ator é o próprio habitante da cidade, no segundo caso, a televisão inaugura um espaço que se publiciza à distância e através de um espetáculo cuja cena está distante do espectador e sobre a qual ele não decide. No primeiro caso, o espetáculo e essencialmente dado à visualidade e diretamente preso à etimologia latina da palavra (spectaculum), no segundo caso, o espetáculo se torna concretamente invisível e camufla sua produção e, sobretudo, seus objetivos persuasivos em relação a uma escala de valores e comportamentos que, invisível, é apenas consumida.

Nessa subversão sígnica do espaço programado pela imagem que se publiciza a fim de convencer e se torna persuasivamente pública está a contradição básica da imagem mediada tecnologicamente. Ante a sua auto-suficiência visual, a realidade se apaga ou se mascara ou não se deixa reconhecer, porque surge saneada das diferenças vividas que narravam o espetáculo do espaço público ao qual o sujeito pertencia e com o qual se identificava. 
Nessa programação de um espaço público apenas possível, reside a alienação social apontada como a grande ameaça da modernidade.

\subsection{O espaço público em conexão}

Prolongando e desenvolvendo o eletrônico, a mídia digital também se apóia na estrutura semiótica da imagem, mas sua visualidade é distinta, pois ela patrocina uma segregação do espaço físico ao produzir o tempo simultâneo. Comprimidos, tempo e espaço não são físicos, não têm paisagens ou referências reais ou fictícias, ao contrário, são imaginários e virtualmente abertos à informação e à comunicação. Trata-se de uma visualidade sem imagem, porque desnutrida de qualquer apoio físico, programado e comercialmente oferecido ao usuário. Mais do que deslocado, o espaço digital é virtual, ou seja, nem público e nem privado, anti-tradicional e sem fala, sem identidade ou emblemas, mas claramente a-temporal, sem passado, sem memória que caracterizam a identidade e o pertencer. Altera-se a compreensão do domínio público pela omissão do seu espaço que, agora, não se desloca, porque é virtual, mas simplesmente acena como informação a ser processada. É o espaço público do mega-mundo eletrônico e das metrópoles com mais de dez milhões de habitantes.

Sua única possibilidade concreta está contida num estranho espaço público da memória coletiva que se intitula rede ou banco de dados voltado para a rápida mudança da informação que não se soma no tempo, mas se multiplica relacionalmente. Logo, a única possibilidade de retenção dessa informação para o domínio público está no espaço daquela memória coletiva e, mais do que nunca, é necessário salvar e nomear a informação que, apressada, está fadada a perderse ante qualquer impulso de um dígito distraído.

Saber acessar, navegar na rede, conectar são as defesas virtuais que substituem as muralhas e portas da cidade antiga ou a reclusão que distinguia o domínio privado do público. Essa competência conectiva é tão eficiente quanto prescritiva e indispensável para ter acesso à informação, à interação e à troca virtual, mas é atópica porque não oferece caminhos a percorrer ou premissas a 
desenvolver. Tudo é rápido, original, virtual. Agora, a visualidade expositiva do espetáculo, o envolvimento do entretenimento e do ócio são substituídos por um contacto secreto entre pessoas que podem não se conhecer, mas convivem num diálogo anônimo sem a espessura do contacto.

Porém e mais do que nunca, o espaço público valoriza a mediação que vai muito além dos programas, siglas e códigos dos sistemas eletrônicos e, até mesmo, da simples informação disponível na rede, pois exige a operação relacional da informação para produzir conhecimento. Ou seja, o que se movimenta no espaço virtual não é a informação, mas a conexão entre informações.

Sem fala e sem imagens, o espaço virtual da rede pública dos sistemas de informação não se faz através do diálogo ou do monólogo que caracterizavam os dois casos anteriores, mas ele está disponível para todos, não é de ninguém e sua apropriação está sujeita à rápida transformação e à substituição dos dados colocados em rede, logo, sua percepção não garante identidade, originalidade ou segurança. Ao contrário, é relacional como convém aos processos de informação que serão tanto mais eficazes ou relevantes quanto mais públicos forem seus processos relacionais: nessa publicidade, o lugar esvazia-se de sentido porque se concentra no instante da própria relação estabelecida e cria uma outra dimensão do coletivo. Atualiza-se no instante fugaz do tempo simultâneo em que alguém se apropria de informações produzidas por outros para construir relações e respostas geradoras de outros conhecimentos: essa mútua modelação do conhecimento cria coesão pública entre indivíduos espalhados em vários pontos privados do planeta. Saber operar com quantidade de informações, comparar, selecionar e relacionar são as operações que desenham o espaço público virtual e se opõe ao cultivo dos hábitos, hierarquias, gestos falas e fabulações que nortearam a doxa do espaço público espetacular. No espaço público virtual o lema é "sair do casulo" ou seja, redimem-se "as tiranias da intimidade" e, ao mesmo tempo, supera-se a exponibilidade do ver para ser visto.

No virtual, a esfera pública é um espaço que não está, mas se processa em desafios reflexivos onde o que importa é estar informado; paradoxalmente, esse hiper domínio público jamais alcançado 
pelo espaço físico ou mediado pela imagem eletrônica, parece produzir uma desconstrução das duas modalidades anteriores. Como observa Pierre Levy (1996, p. 16) o espaço fictício é exatamente como o real, só lhe falta a existência, ao contrário, o espaço virtual se opõe não ao real, mas ao atual porque é sua alternativa disponível para a ação capaz de superar a distância que os separa. $O$ virtual é a ante-sala da ação que concretiza a passagem do virtual ao atual, do privado ao público, do indivíduo ao coletivo, da objetivação da interioridade à subjetivação da exterioridade. Entre estes pólos que permaneciam estanques no espaço cosmopolita, no público virtual as fronteiras nítidas dão lugar a uma fractalização das repartições (Levy,1996, p. 25).

O espaço público do lugar tradicional tem na doxa, transmitida e mantida pela fabulação oral, o princípio ético da sua semiosfera. O espaço mediado pela imagem autofágica e comercial é claramente submisso a um interesse programado e sua ética está contida na própria eficiência técnica ficcional. A rede pública de informação do espaço virtual, ao contrário, é dominada pela acessibilidade, transmissão e armazenamento da informação inerentes ao veículo digital. Abre-se um novo debate entre o público e o privado, entre o lugar e o mundo, entre a cidade desconhecida e a mega-cidade porque, mais cedo ou mais tarde, se descobre que os eventos, os espaços e as criações são acessíveis a todos. Reinventa-se o "espaço banal" (Santos,1996, p. 258) como novo espaço possível para o desenho do mundo. Se a quantidade de informação é condição indispensável para selecionar, avaliar e escolher entre alternativas e dar qualidade crítica à ação, a tecnologia que caracteriza o espaço público virtual oferece a condição que garante crescentes relações comunicativas entre cidadãos do mundo num complexo espaço público planetário. Concretizar esse espaço, hoje utópico, é o desafio do nosso tempo. 